\title{
ANALISIS ANTIOKSIDAN EKSTRAK ETIL ASETAT DARI KULIT BUAH RAMBUTAN (Nephelium lappaceum) DENGAN MENGGUNAKAN METODE DPPH (1,1 difenil-2-pikrilhidrakzil)
}

\author{
Nurfadillah, St Chadijah, Waode Rustiah \\ Jurusan Kimia, Fakultas Sains dan Teknologi, UIN Alauddin Makassar \\ Email: Nurfadillahrais@gmail.com
}

\begin{abstract}
Rapiah rambutan fruit leather (Nephelium lappaceum) is one of the traditional medicine to cure various diseases such as fever and dysentery. Scientific research previously stated rambutan fruit peel skin Rapiah rambutan (Nephelium lappaceum) potentially have antioxidant content. Through this research can know the effect of solvent ethyl acetate to extract optimal rambutan fruit skin in antioxidants withdrawal. The method used for extraction is macerated using methanol and partitioned with liquid-liquid extraction using ethyl acetate solvent with a ratio (1:3), (1:4) and (1:5) which produces a thick rind extract rambutan. The extract was tested color and separated by thin layer chromatography (TLC) using the eluent butanol: glacial acetic acid: water (BAA) (4: 1: 5). Antioxidants are determined by testing against DPPH free radicals by measuring the absorbance of DPPH (1,1-diphenyl-2-pikrilhidraksil) at a wavelength of $517 \mathrm{~nm}$. So that the results of this study showed the highest \% reduction obtained at a ratio (1:3).
\end{abstract}

Keywords: Leather rambutan, antioxidant and DPPH

\section{PENDAhuluan}

Indonesia merupakan negara yang kaya akan keanekaragaman tanaman. Terdapat lebih dari 30.000 jenis tanaman yang ada di Indonesia, 2.000 - 3.000 jenis di antaranya merupakan tanaman yang berkhasiat sebagai obat. Salah satu tanaman yang dapat digunakan sebagai obat adalah buah rambutan (Nephelium lappaceum).

Buah rambutan (Nephelium lappaceum) merupakan buah musiman yang berasal dari daerah tropis yang mempunyai daun terpencar, dengan warna tangkai merah kecoklatan. Bunganya terbentuk malai, terletak pada ketiak daun atau ujung cabang, mempunyai daun pelindung kecil, berbekas-bekas dan baunya agak harum. Tanaman rambutan menghasilkan limbah yang berupa kayu, daun, kulit dan biji buahnya. Akan tetapi, secara tradisional tanaman rambutan digunakan untuk pengobatan banyak penyakit, antara lain kulit buahnya untuk mengatasi disentri dan demam, kulit kayu untuk mengatasi sariawan, daun untuk mengatasi diare dan menghitamkan rambut, akar untuk mengatasi demam serta bijinya untuk mengatasi diabetes mellitus. 
Dalam buah rambutan yang paling berpotensi sebagai antioksidan adalah kulitnya. Namun kulit buah rambutan tersebut belum banyak dimanfaatkan dan hanya digunakan sebagai limbah. Untuk itu perlu pemanfaatan yang lebih lanjut dari kulit buah rambutan sebagai antioksidan. Berdasarkan penelitian Thitilertdecha, et al (2010), kandungan fenolik dari kulit buah rambutan antara lain berupa geraniin, corllagin, yang merupakan golongan flavonoid, dan asam elagat dari golongan tanin. Dari kandungan kulit buah rambutan tersebut dapat dijadikan sebagai antioksidan untuk menangkal radikal bebas yang terdapat dalam tubuh yang mampu mengakibatkan penyakit generatif misalnya kanker.

Radikal bebas merupakan senyawa yang mengandung elektron tidak berpasangan yang bertindak sebagai akseptor elektron. Radikal bebas ini berbahaya karena sangat reaktif mencari pasangan elektronnya. Radikal bebas ini memerlukan elektron yang berasal dari pasangan elektron molekul sekitarnya. Radikal bebas yang terbentuk dalam tubuh akan menghasilkan radikal bebas baru melalui reaksi berantai yang akhirnya jumlah terus bertambah dan menyerang tubuh. Radikal bebas yang umumnya digunakan sebagai model dalam penelitian antioksidan atau peredam radikal bebas adalah; 1,1 difenil-2-pikrilhidrakzil (DPPH).

DPPH merupakan senyawa radikal bebas yang paling stabil dibandingkan dengan contohcontoh radikal yang lainnya, sehingga apabila digunakan sebagai pereaksi cukup dilarutkan dan tidak perlu dibuat recenter paratus dengan cara mereaksikan pereaksi-pereaksi sebagaimana yang dilakukan pada radikal bebas nitrit oksida. Senyawa ini jika disimpan dalam keadaaan kering dan kondisi penyimpanan yang baik akan tetap stabil selama bertahun-tahun. Uji aktivitas antioksidan menggunakan metode DPPH dipilih karena ujinya sederhana, mudah, cepat dan peka serta hanya memerlukan sedikit sampel.

Metode yang digunakan untuk mengujikan antioksidan pada kulit buah rambutan menggunakan metode maserasi, yang merupakan proses penyaringan dengan cara sampel direndam dalam pelarut sampai meresap dan melunakkan susunan sel, sehingga zat-zat mudah larut. Yang kemudian dipartisi cair-cair dengan etil asetat agar dapat menarik semua yang ada pada sampel baik yang bersifat polar maupun non polar sehingga ekstrak antioksidan yang diperoleh lebih banyak.

Untuk mengetahui seberapa besar daya peredamnya dilakukan pengukuran secara spektrofotometer UV-Vis. Prinsip pengukuran secara spektrofotometer UV-Vis adalah mengukur besarnya absorbansi pemucatan warna larutan DPPH dengan panjang gelombang maksimum.

Dari latar belakang di atas maka dilakukan penelitian analisis antioksidan ekstrak etil asetat dari kulit buah rambutan dengan menggunakan metode DPPH. 
Nurfadillah, St. Chadijah,

\& Waode Rustiah

\section{METODE PENELITIAN}

Alat

Alat yang digunakan dalam penelitian ini yaitu: spekrofotometer UV-Vis, sinar ultraviolet, lemari asam, evaporator, oven, neraca analitik, alat-alat gelas, bulp, pisau, toples dan botol semprot.

\section{Bahan}

Bahan yang digunakan dalam penelitian ini yaitu aquadest, aluminium foil, etil asetat, metanol, eluen (butanol:asam asetat glasial : air (BAA) (4:1:5), kristal DPPH (1,1 difenil-2pikrilhidrazil), kulit buah rambutan (Nephelium lappaceum) dan plat KLT.

\section{Prosedur Penelitian}

\section{Persiapan Bahan}

Sampel yang digunakan yaitu buah rambutan yang diperoleh dari pohon yang berada di Bulukumba Sulawesi Selatan. Buah rambutan yang diambil adalah buah rambutan yang siap dipetik dan yang sudah tua, kemudian dipisahkan dari daging buahnya menggunakan pisau sehingga yang diperoleh kulit dari buah rambutannya saja. Kemudian kulitnya dibersihkan dari sisa-sisa daging buah rambutan yang masih menempel, selanjutnya dikeringkan pada suhu kamar kemudian digiling hingga menjadi serbuk.

\section{Proses Maserasi}

Serbuk kulit buah rambutan ditimbang sebanyak $1 \mathrm{~kg}$ kemudian dimaserasi (perendaman) dengan menggunakan metanol selama 3 × 24 jam. Selanjutnya fitrat hasil maserasi pertama, kedua dan 3 digabungkan lalu dikeringkan dengan menggunakan rotary evaporator sehingga diperoleh ekstrak kental.

\section{Proses Ekstraksi Cair-Cair}

Ekstrak kental hasil maserasi diekstraksi cair-cair dengan cara dimasukkan dalam corong pisah dengan perbandingan etil asetat (1:3), (1:4), (1:5) dalam $100 \mathrm{~mL}$. Kemudian dikocok hingga terjadi pemisahan pelarut. Setelah itu dipekatkan dengan dievaporasi sehingga menghasilkan ekstrak etil asetat.

\section{Pembuatan Larutan Induk Ekstrak Etil Asetat Kulit Buah Rambutan 1000 ppm}

Ekstrak etil asetat dibuat larutan induk pada konsentrasi 1000 ppm dengan menimbang 100 mg ekstrak kental, kemudian ditambah larutan metanol sampai volume $100 \mathrm{~mL}$. 
Nurfadillah, St. Chadijah,

\& Waode Rustiah
Analisis antioksidan ekstrak etil asetat dari kulit buah rambutan (nephelium lappaceum) dengan menggunakan metode DPPH (1,2 difenil2-pikrilhidrakzil)

\section{Pembuatan Deret Kerja Ekstrak Etil Asetat Kulit Buah Rambutan}

Dari larutan induk ekstrak etil asetat kulit buah rambutan 1000 ppm dibuat masingmasing konsentrasi (12 ppm, 14 ppm, 16 ppm, 18 ppm dan 20 ppm) dalam 10 mL.

\section{Pembuatan Larutan DPPH 40 ppm}

Kristal DPPH $4 \mathrm{mg}$ dilarutkan dalam metanol sampai $100 \mathrm{~mL}$ sehingga didapatkan konsentrasi 40 ppm. Larutan ini segera digunakan dan dijaga tetap terlindungi dari cahaya.

\section{Uji Daya Antioksidan Ekstrak Etil Asetat Kulit Buah Rambutan Secara Kualitatif}

a. $10 \mathrm{mg}$ ekstrak etil asetat untuk tiap perbandingan ditambahkan 5 tetes DPPH 40 ppm. Jika warna larutan akan berubah dari ungu menjadi kuning.

b. Ekstrak dari kulit buah rambutan ditotolkan pada lempeng silika gel yang selanjutnya dielusi dengan fase gerak butanol:asam asetat glasial : air (BAA) (4:1:5). Setelah dielusi lempeng dikeringkan dan disemprotkan dengan larutan DPPH 40 ppm dalam metanol. Dalam waktu 30 menit komponen ekstrak yang bersifat anti radikal bebas menghasilkan bercak kuning pucat dengan latar belakang ungu.

\section{Uji Antioksidan Ekstrak Etil Asetat Kulit Buah Rambutan Secara Kuantitatif}

Larutan uji masing-masing dipipet sebanyak $2 \mathrm{~mL}$ ke dalam botol vial kemudian ditambahkan $1 \mathrm{~mL}$ larutan DPPH 40 ppm, campuran ini dihomogenkan dan diinkubasi selama 30 menit agar bereaksi secara sempurna, selanjutnya diukur absorbansi dengan spektrofotometer UV-Vis pada panjang gelombang maksimum.

\section{HASIL DAN PEMBAHASAN}

\section{Preparasi sampel}

Buah yang digunakan perlu disortasi tujuannya untuk memisahkan benda-benda asing seperti bagian-bagian tanaman yang tidak diinginkan dan pengotoran lain yang masih tertinggal sehingga yang tersisa adalah kulit buahnya. Selanjutnya dilakukan pengeringan dengan dianginkan di udara terbuka tanpa terkena cahaya matahari langsung karena akan merusak metabolit sekunder pada kulit buah tersebut. Proses pengeringan akan mengurangi kadar air, sehingga suhu dan waktu pengeringan dapat mempengaruhi. Suhu pengeringan tergantung pada jenis bahan yang dikeringkan. Suhu yang digunakan dalam proses pengeringan ini adalah suhu kamar yaitu sekitar suhu $30^{\circ} \mathrm{C}$. Untuk uji antioksidan tidak boleh menggunakan suhu tinggi dalam pengeringan, karena akan mempengaruhi hasil uji. Pengeringan dilakukan bertujuan untuk 
mendapatkan sampel yang tidak mudah rusak oleh adanya pertumbuhan jamur sehingga dapat disimpan dalam waktu yang lebih lama. Selanjutnya sampel dihaluskan dalam bentuk serbuk, hal ini bertujuan untuk mempermudah proses penarikan zat aktif pada saat dimaserasi. Serbuk yang telah kering selanjutnya disimpan dalam wadah bersih, kering dan terlindungi oleh cahaya matahari untuk mencegah kerusakan.

\section{Proses Ekstraksi}

Proses maserasi dilakukan selama 3 X 24 jam, semakin lama waktu ekstraksi kesempatan untuk bersentuhan makin besar sehingga hasilnya juga bertambah sampai titik jenuh larutan. Kontak antara sampel dan pelarut dapat ditingkatkan apabila dibantu dengan pengadukan agar kontak antara sampel dan pelarut semakin terjadi, sehingga proses ekstraksi lebih sempurna. Pelarut yang digunakan dalam penelitian ini adalah metanol tehnis yang terlebih dahulu dimurnikan. Pemilihan pelarut ini karena metanol merupakan pelarut yang ekonomis dan mudah didapat. Selain itu, peralut metanol mampu menarik senyawa metabolik sekunder yang bersifat polar pada kulit buah rambutan misalnya fenolik dan flavonoid. hasil maserasi kulit rambutan dengan metanol berupa ekstrak kental berwarna hitam dengan rendemen 6,30265 \%.

Ekstrak yang diperoleh dikeringkan sampai pelarut habis menguap atau kering. Lalu dibuat suatu perbandingan yaitu (1:3), (1:4) dan (1:5) kemudian dilakukan pemisahan partisi menggunakan corong pisah dengan perbandingan tersebut. Ekstraksi cair-cair menggunakan etil asetat bertujuan untuk menarik semua senyawa yang tedapat pada kulit buah rambutan baik yang bersifat polar maupun non polar. Agar terjadi suatu pemisahan, selain menggunakan etil asetat digunakan pula metanol dan air dengan perbandingan tertentu, pada proses pemisahan tersebut terdapat dua fase, dimana yang berada diatas adalah senyawa-senyawa yang ikut dalam etil sedangkan yang berada dibawah adalah ekstrak metanol. Setelah diperoleh senyawa yang ikut dalam etil asetat, kembali diuapkan dengan rotary evaporator. Untuk hasil yang diperoleh dari ekstraksi cair-cair ekstrak etil asetat kulit buah rambutan dapat dilihat pada tabel.

Tabel 1. Hasil Partisi Cair-Cair Ekstrak Etil Asetat Kulit Buah Rambutan

\begin{tabular}{cccc}
\hline \multirow{2}{*}{ No. } & Perbandingan sampel & \multicolumn{2}{c}{ Bobot (gram) } \\
\cline { 3 - 4 } & & I & II \\
\hline 1. & $1: 3$ & 14,6276 & 11,1903 \\
2 & $1: 4$ & 12,9584 & 8,4039 \\
3 & $1: 5$ & 7,2456 & 5,3038 \\
\hline
\end{tabular}




\section{Uji Antioksidan Ekstrak Kulit Buah Rambutan Secara Kualitatif}

Uji warna

Pada tahap uji warna, dilakukan dengan cara menimbang ekstrak kulit buah rambutan sebanyak 0,01 gram kemudian ditambahkan dengan 5 tetes DPPH. Dari percobaan yang telah dilakukan membuktikan bahwa dalam sampel yang diuji positif memiliki antioksidan, hal ini ditandai dengan adanya perubahan warna dari ungu pucat menjadi kuning pucat. Penambahan DPPH pada uji warna berfungsi sebagai radikal bebas yang akan bereaksi dengan antioksidan yang terdapat pada buah rambutan. Perubahan warna terjadi karena adanya reaksi reduksi DPPH dari senyawa peredam radikal bebas. Reaksi dapat dilihat pada gambar

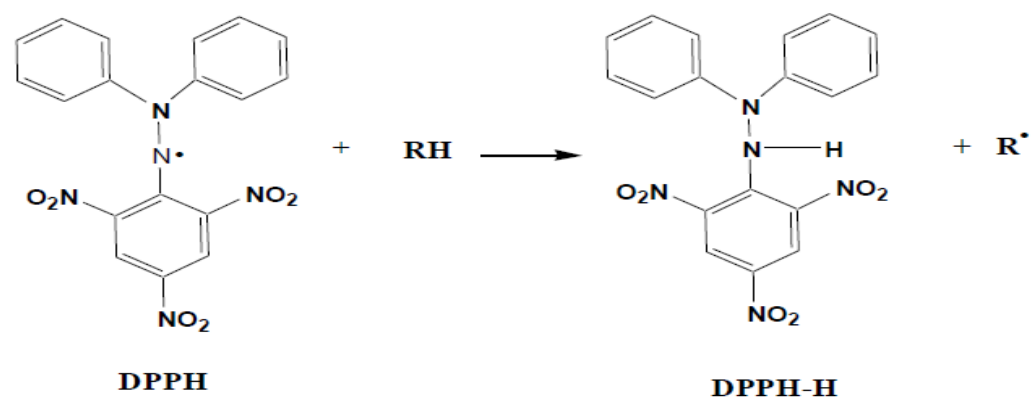

Gambar 1. Reduksi DPPH dari Senyawa Peredam Radikal Bebas

\section{Uji antioksidan secara KLT}

Uji ini bertujuan untuk mengetahui adanya senyawa aktif di dalam ekstrak yang memiliki aktivitas antioksidan dalam meredam radikal (DPPH). KLT merupakan metode pemisahan suatu senyawa berdasarkan perbedaan distribusi dua fase yaitu fase diam dan fase gerak. Fase diam yang digunakan adalah plat silika gel yang bersifat polar, sedangkan eluen yang digunakan sebagai fase gerak adalah BAA yang juga bersifat sangat polar. BAA dipilih karena dari komposisi eluen tersebut bersifat sangat polar karena mengandung air, kepolaran fase diam dan fase gerak hampir sama tetapi masih lebih polar fase gerak sehingga senyawa yang dipisahkan terangkat mengikuti aliran eluen, hal ini disebabkan karena kandungan senyawa yang terdapat pada kulit buah rambutan yaitu berupa fenolik dan flavonoid bersifat polar.

\section{Uji antioksidan ekstrak kulit buah rambutan secara kuantitatif}

Uji kuantitatif daya antioksidan pada penelitian ini dilakukan dengan metode DPPH menggunakan prinsip spektrofotometri UV-Vis. Senyawa yang dimiliki antioksidan akan mendonorkan atom hidrogennya untuk berikatan dengan DPPH membentuk DPPH tereduksi yang ditandai dengan kehilangan warna ungu menjadi kuning pucat disertai penurunan nilai absorbansi. 
<smiles>O=[N+]([O-])c1cc([N+](=O)[O-])c(N(c2ccccc2)N(c2ccccc2)c2ccccc2)c([N+](=O)[O-])c1</smiles>

DPPH

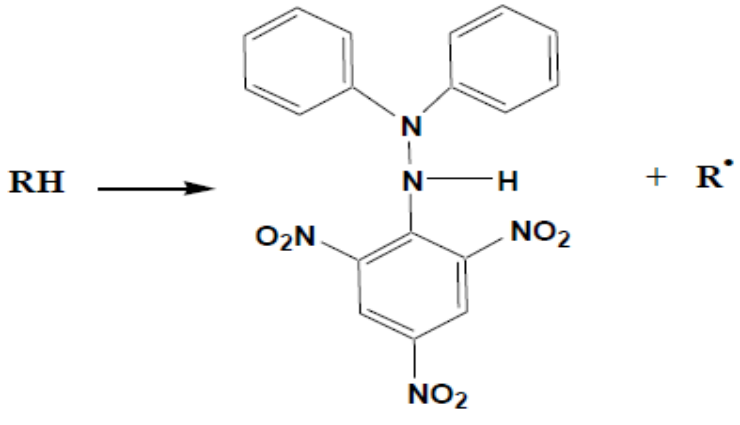

DPPH-H

Panjang gelombang untuk pengukuran antioksidan dengan metode peredaman DPPH adalah pada panjang gelombang $517 \mathrm{~nm}$ dimana serapan DPPH maksimum yang ditandai dengan adanya puncak.

Untuk mengetahui daya serap antioksidan pada radikal bebas pada DPPH dapat dihitung dengan peredaman radikal bebas $(\%)$

$$
\% \text { peredaman }=\frac{A_{D P P H}-A_{\text {sampel }}+D P P H}{A_{D P P H}} \times 100 \%
$$

peredaman radikal bebas (\%) yang diperoleh telah sesuai dengan teori bahwa semakin tinggi konsentrasi maka semakin tinggi pula nilai peredamannya (berbanding lurus).

Tabel 2. Hubungan Antara Konsentrasi Kulit Buah Rambutan

\begin{tabular}{ccccccc}
\hline $\begin{array}{c}\text { Konsetrasi } \\
\text { (ppm) }\end{array}$ & \multicolumn{3}{c}{ Absorbansi } & \multicolumn{3}{c}{ Peredaman radikal bebas (\%) } \\
\cline { 2 - 7 } $\mathbf{1 : 3}$ & $\mathbf{1 : 4}$ & $\mathbf{1 : 5}$ & $\mathbf{1 : 3}$ & $\mathbf{1 : 4}$ & $\mathbf{1 : 5}$ \\
\hline 12 & 0,079 & 0,136 & 0,064 & 94,57 & 90,75 & 95,58 \\
14 & 0,071 & 0,103 & 0,055 & 96,15 & 92,96 & 96,21 \\
16 & 0,054 & 0,087 & 0,051 & 96,31 & 94,09 & 96,48 \\
18 & 0,044 & 0,052 & 0,050 & 96,96 & 96,46 & 96,58 \\
20 & 0,026 & 0,035 & 0,045 & 98,22 & 97,62 & 96,89 \\
\hline
\end{tabular}




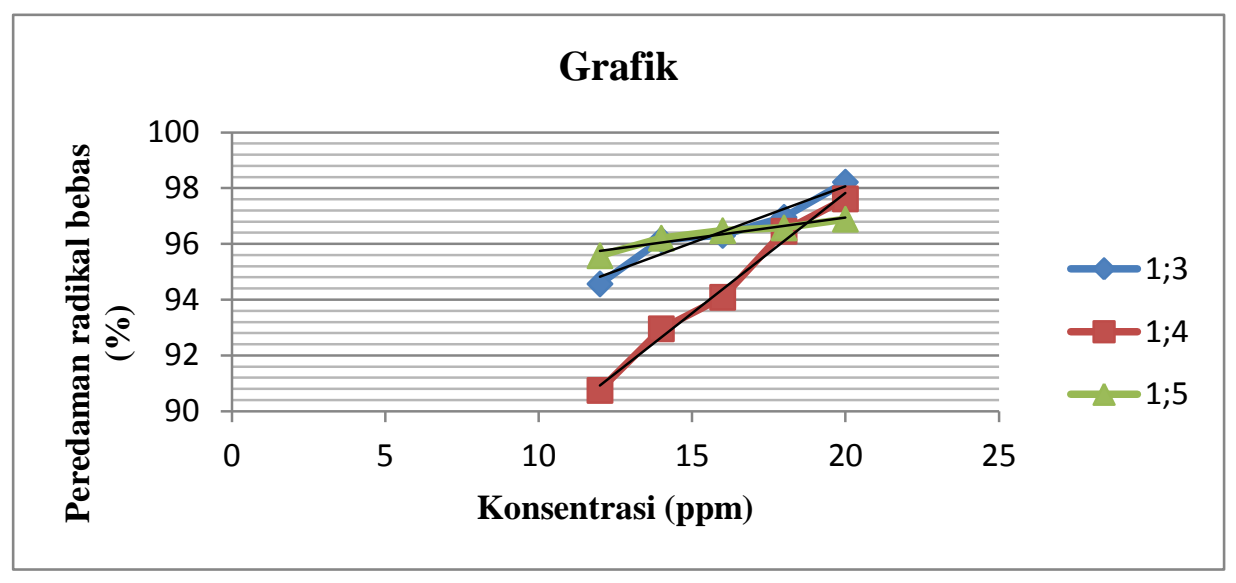

Gambar 2. Grafik Hubungan Antara Konsentrasi Kulit Buah Rambutan dengan Peredaman Radikal Bebas (\%).

Jika semakin tinggi nilai peredaman radikal bebas (\%) maka semakin bagus pula daya serap antioksidan tersebut untuk menangkal radikal bebas pada DPPH. Dari ketiga perbandingan tersebut (1:3), (1:4) dan (1:5) dengan konsentrasi yang sama yang memiliki peredaman radikal bebas (\%) yang paling tinggi adalah (1:3). Sehingga pada penelitian ini dapat disimpulkan bahwa penambahan etil asetat tidak berpengaruh karena semakin banyak etil asetat yang digunakan pada ekstraksi cair-cair maka peredaman radikal bebas (\%) akan semakin menurun. Tingginya penyerapan antioksidan pada perbandingan (1:3) dapat pula dilihat pada bobot ekstraksi cair-cair dimana perbandingan (1:3) memiliki bobot yang paling tinggi dibandingkan dengan perbandingan (1:4) dan (1:5).

Apabila dibandingkan dengan penelitian Dewi Maulida dan Naufal Zurkarnaen tentang ekstraksi antioksidan (likopen) dari buah tomat, hasil yang diperoleh berbeda dengan hasil penelitian yang dilakukan, pada ekstraksi antioksidan (likopen) dari buah tomat peredaman radikal bebas (\%) yang baik diperoleh pada perbandingan 1:4 sedangkan hasil penelitian yang dilakukan yaitu tentang analisis antioksidan dari kulit buah rambutan peredaman radikal bebas (\%) yang baik diperoleh pada perbandingan 1:3. Hal ini disebabkan karena adanya perbedaan sampel, pelarut serta perbandingan yang digunakan.

\section{PENUTUP}

\section{Kesimpulan}

Berdasarkan hasil yang diperoleh dari penelitian ini dapat disimpulkan bahwa semakin tinggi konsentrasi ekstrak etil asetat maka semakin besar pula peredaman radikal bebasnya. Dari 
ketiga perbandingan tersebut ekstrak etil asetat kulit buah rambutan yang paling baik untuk meredam radikal bebas DPPH yaitu terdapat pada perbandingan 1:3.

\section{Saran}

Perlu penelitian lebih lanjut mengenai penentuan struktur dari senyawa antioksidan pada kulit buah rambutan dengan menggunakan spektrofotometer NMR.

\section{DAFTAR PUSTAKA}

Dewi Kusuma Arifia, Lestari Umie, dan Lestari Sri Rahayu, "Efek Ekstraksi Kulit Buah Rambutan Terhadap Peroksida Lipid Hepar Tikus Obesitas", Universitas Negeri Malang (Maret, 2012), vol 1. No. 1 (17 Januari 2014).

Dwi SriRahayu, Dra. Dewi Kusrini M.Si dan Dra.Enny Fachriyah M.Si, "Penentuan Aktivitas Antioksidan dari Ekstrak Etanol Daun Ketapang (Terminali acatappa L) denganMetode 1,1-Difenil-2-Pikrilhidrazil (DPPH)," Labortorium Kimia Organik, Jurusan Kimia FMIPA UniversitasDiponegoro, (13 Januari 2014).

Hartanto Hondy, "Identifikasi Potensi Antioksidan Minuman Cokelat Dari Kakao Lindak Dengan Berbagaicara Preparasi: Metode Radikal Bebas DPPH". Skripsi (Universitas Katolik Widya Mandala Surabaya, 2012) (08 Agustus 2014).

Hayati, KamilahElok, "Fraksinasi dan Identifikasi Senyawa Tanin Pada daun Belimbing Wuluh", Universitas Islam Negeri Maulana malik Ibrahim: Malang, 2010 (08 Agustus 2014).

Haryoto, Santoro Brotodan Nugroho Hafid,"Aktivitas Antioksidan fraksi Polar Metanol dari Kulit Kayu Batang Shoreaacum inatissima dengan metode DPPH", Universitas Muhammadiyah Surakarta, vol. 8 no. 1 (juli 2007) (15 Januari 2014).

Hertiani Triana, "Daya Antioksidan Ekstrak Etanol Rimpang Temu Kunci Dengan Metode DPPH', Universitas Gadja Mada: Yogyakarta, 2013 (08 Agustus2014).

Maulida Dewi dan Zulkarnaen Naufal,"Ekstraksi Antioksidan (Likopen) Dari Buah Tomat Dengan Menggunakan Solven Campuran, n-Heksan, asetondan Etanol'.Skripsi, Universitas diponegoro (Mei 2010) (10 Agustus 2014).

Saleh Purnawati Lisa, Suryanto Edi danYudistiraadithya, "AktivitasAntioksidan Dari ekstrakTongkolJagung (Zea Mays L.)", FMIPA UNSRAT Manado, vol. 2 no.1 (Juli 2012) (20 Januari 20s14). 